\title{
Interaction of culture and grief amongst women who terminated a pregnancy in adolescence: A narrative approach
}

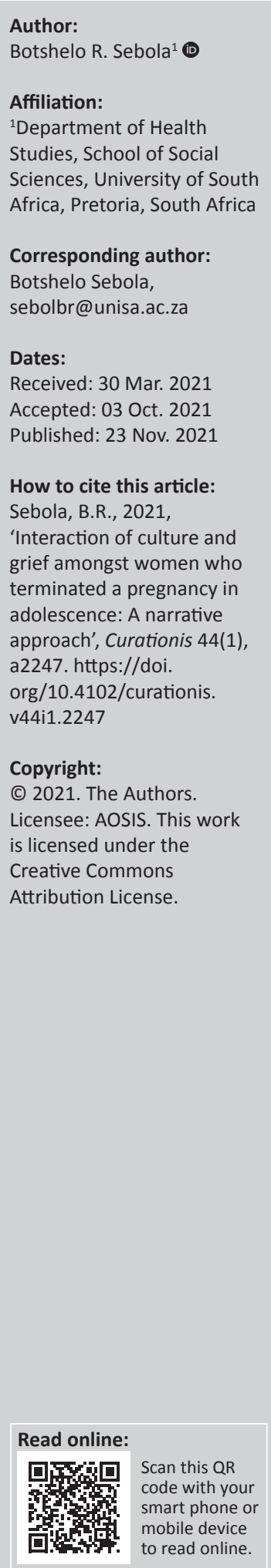

Background: Culture plays a vital role in resolving grief in African communities. However, women who terminate a pregnancy in adolescence are typically not exposed to cultural rituals that could ease their grief.

Objectives: The purpose of this article is to explore the interaction of culture and grief amongst women who terminated a pregnancy in adolescence.

Method: A qualitative exploratory study was undertaken using a narrative approach. Unstructured interviews were conducted to solicit narratives from 11 women who terminated a pregnancy in adolescence.

Results: Data were analysed through narrative, thematic data analysis. Three themes emerged from the findings: delayed post-traumatic growth, low body esteem and an alteration in the development of maternal identity.

Conclusion: The study intended to explore the interaction of culture and grief amongst women who terminated a pregnancy in adolescence. The researcher determined that women who had not honoured their culture because of the secrecy surrounding the termination of pregnancy had delayed healing and an altered self-image.

Keywords: adolescence; approach; culture; grief; interaction; narrative approach; terminated pregnancy; women.

\section{Introduction}

Culture plays a vital role in resolving grief in African communities. Africans are rooted in their cultural beliefs, and tradition permeates almost every aspect of societal rituals, including death and burials (King 2013). Death rituals have played an important role in helping individuals cope with death and celebrate the death of a loved one (Obare 2019). The overall purpose of death rituals is to support those who remain and offer acceptance and a celebration of life for those who have lost a loved one.

As many Africans believe that death, including the death of a foetus (by any means), may result in misfortune if the deceased did not receive a dignified send-off, African cultures enforce the practice of formal death ceremonies. These ceremonies typically involve guests, the slaughtering of an animal, food and prayer in celebrating the life and death of the deceased (Lagat 2018). How death is viewed and celebrated will vary amongst religions and cultures. Death rituals are believed to let the deceased rest in peace and allow the healing of those who are close to the deceased. The Bukusu people of Kenya practice a ritual of naming family members after the deceased, believing that the dead live amongst them and will bless them (Obare 2019). These practices are meaningful and assist the bereaved in healing emotionally. Hoy (2013), in his findings from investigating funeral practices, established five common components of death rituals amongst different cultures, namely: (1) significant symbols, (2) gathered community, (3) ritual action, (4) connection to heritage and (5) transition of the corpse. The significant symbols are used to honour the deceased, the gathered community provides support to the bereaved, the ritual action encourages mourners to be active, connection to heritage symbolises the value of cultural practices and customs and the corpse's presence is normally used in a ritualistic manner (Hoy 2013). A common generalisation is that the execution of these rituals is essential in maintaining harmony and balance between the physical and the spiritual world (Baloyi \& Makobe-Rabothata 2014). 
The World Health Organization (WHO) estimates that close to 21 million adolescent girls aged 15 to 19 years fall pregnant every year and 5.6 million of these pregnancies end in abortion (WHO 2020). The majority of these terminations take place without the knowledge of parents or other support systems. Moreover, adolescents differ from older women undergoing the termination of a pregnancy in several ways. In addition to being intellectually, morally and emotionally less mature, their life experiences and cultural knowledge are limited (Coleman et al. 2007).

\section{Problem statement}

Women who terminated a pregnancy in adolescence are seldom exposed to cultural rituals related to death that could afford them a reprieve from their grief. The stigma related to the termination of pregnancy causes many of these women not to openly acknowledge their loss but rather grieve in silence, thereby forsaking public mourning and subsequent social support (Doka 2009).

Whilst cultural rituals play a significant role in easing grief in African communities, in South Africa, the setting of this study, there is limited research on the interaction of culture and grief amongst women who terminated a pregnancy during adolescence. As most women who terminated a pregnancy in adolescence are not knowledgeable about cultural death rituals that could ease their grief, there is a need to explore the interaction of culture and grief amongst women who terminated a pregnancy in adolescence.

\section{Purpose}

The purpose of this study was to explore the interaction of culture and grief amongst women who terminated a pregnancy in adolescence.

\section{Objectives}

- To describe the role played by culture in the resolution of grief

- To describe how culture and grief interact

\section{Definition of key concepts}

\section{Adolescence}

Adolescence is a phase of life when a person is transitioning from childhood to adulthood. This transformation is marked by the maturity of sexual functioning (Kinghorn et al. 2018; Weiten 2013). Though there are varying views, but adolescence is often understood as the age between 10 and 24 years (Bruce, Lunt \& McDonagh 2017; Sawyer et al. 2018; Weiten 2013). This study aligns with the South African view, which defines adolescents as those aged between 10 and 19 years (Health e-News 2015).

\section{Culture}

De Oliveira Cardoso et al. (2020) defined culture as:
$[A]$ way in which societies structure the role of rites and rituals. Rite includes a broader category such as the rite of passage, or healing, while the ritual is a set of gestures and actions that make the rites. (p. 2)

The researcher used this definition to apply the context of culture in this article. Within each culture there is a mix of death rituals, beliefs about death and traditions related to burial as well as expectations about maternal identity and the woman's protection of her pregnancy (Souza \& Souza 2019). For women who are grieving the termination of a pregnancy, these African cultural practices, if followed, could help promote a feeling of emotional stability, security and emotional healing.

\section{Grief}

Grief has specific social and cultural meanings. Delahanty and Washburn (2014) explained grief as a universal emotional experience that most people go through following the loss or death of a loved one. However, there are a variety of individual differences concerning the intensity, duration and ways of expressing this emotion (Genevro, Marshal 1 \& Miller 2004). Feelings of anger, sadness, social and intellectual difficulties are typical of the experience of loss. With time comes acknowledgement and acceptance, and these emotions are normally resolved; gradually, the grieving person is able to reflect and normalise their situation (Genevro et al. 2004; Swan et al. 2021).

\section{Interaction}

According to Wang, Elston and Zhu (2011), interaction relates to the transitional action between things; it can be understood as the reciprocal influence between culture and grief. In this study, the interaction between culture and grief means that the cultural practices around death could have a positive or negative impact on those left behind, depending on whether these practices are properly adhered to. African traditional religion requires specific burial rituals to ensure a proper sendoff for the departed and avoid potential disasters (Ezenweke 2008; Obasi 2002). Therefore, a woman who terminated a pregnancy but failed to provide an appropriate send-off for the foetus may be haunted by the fear of impending calamities.

\section{Research methods and design}

A qualitative, exploratory, narrative methodology (Trahar 2009) was followed to explore the stories of 11 women who terminated a pregnancy in adolescence and their experiences of the interaction of culture and grief. The study was conducted in Gauteng, South Africa. The researcher's contact details were included in the consent form, and the participants were asked to contact the researcher or the Chair of the Review Board should they have any questions regarding the study.

\section{Sampling and participants}

Purposive and snowball sampling techniques were used to recruit 11 participants who terminated a pregnancy 
in adolescence. Women who terminated a pregnancy in adolescence were difficult to recruit because of the stigma attached to this phenomenon in most African societies (Loi et al. 2018). Participants were recruited through a community health centre that works with women who want to terminate a pregnancy. The centre's management distributed flyers to potential participants, containing an invitation to be part of the study, the purpose of the study, expectations of participants, benefits of the study, an overview of participants' rights and confidentiality and the Chair of the Review Board and researcher's contact details. Through this sampling method, five potential participants contacted the researcher and were willing to participate in the study. The snowball technique was then used to recruit an additional six participants (Berg 2001; Cohen \& Arieli 2011). All the participants had to meet pre-determined inclusion criteria, namely (1) participants had to be women aged between 20 and 50 years, (2) residing in Gauteng province of South Africa and (3) had terminated a pregnancy in adolescence.

\section{Informed consent}

A thorough explanation about the study was given to the participants who called and expressed an interest in taking part. Participants were asked to sign a consent form after they were informed about the study's intent and how the findings would be used. The consent form also stipulated that participants should not use their names but pseudonyms to ensure their confidentiality. The consent form was signed at a place and time agreed upon by both the researcher and the participant. After signing the consent form, an interview appointment was scheduled and participants were asked not to use their airtime to call the researcher but to alert her of their availability so that she could contact them. The issue of voluntarism was emphasised throughout the study and participants were free to withdraw from the study at any time.

\section{Data collection}

Data were collected from July 2017 to December 2017. Unstructured audio-recorded interviews were conducted to solicit data from 11 women who terminated a pregnancy in adolescence. Participants gave their permission for the interviews to be recorded. In accordance with the narrative approach to data collection, the interviews started with a broad opening statement: 'Tell me how culture has interacted with your grief after you terminated a pregnancy in adolescence'. Participants freely shared how their failure to engage in cultural rituals affected them and explained the connection between culture, grief and moving on with their lives. A set of probing questions were prepared, but they were ultimately not required because the participants gave a detailed account of their experiences during the interviews. Such questions included: (1) How has your failure to engage in cultural rituals affected you? (2) How do you feel after terminating a pregnancy? and (3) Does culture and grief, and moving on with your life, have any connection?

\section{Data analysis}

The interviews were transcribed verbatim, and the researcher read them several times to gain an understanding of the participants' experiences (Riessman 2008). The interviews were envisioned as units of analysis. Sentences were viewed as units of meaning that were later compressed according to their content and codes; the codes were furthermore arranged into categories and subcategories based on similarities. Ultimately, themes were formulated from these categories. A sample of the transcripts was then given to participants to confirm whether their views had been captured clearly, and they all confirmed that the transcript was a true reflection of their experiences (Kaewkungwal \& Adams 2019).

\section{Findings of the study}

The participants were aged between 20 and 42 years (see Table 1). Six participants had terminated a pregnancy after being coerced by their parents or partners; they were unwilling to terminate but believed they did not have a choice at the time. Four participants terminated a pregnancy out of fear of being found out and one participant terminated pregnancy as a way of getting back at her partner, who had been involved in many relationships. The data analysis revealed three themes: delayed post-traumatic growth, low body esteem and an alteration in the development of a maternal identity.

\begin{tabular}{|c|c|}
\hline Biographic characteristics & Frequency $(N=11)$ \\
\hline \multicolumn{2}{|l|}{ Age } \\
\hline $20-24$ years & 4 \\
\hline $25-29$ years & 2 \\
\hline $30-34$ years & 2 \\
\hline $35-50$ years & 3 \\
\hline \multicolumn{2}{|l|}{ Level of education } \\
\hline Primary education & 2 \\
\hline Secondary education & 6 \\
\hline Tertiary education & 3 \\
\hline \multicolumn{2}{|l|}{ Ethnicity } \\
\hline Tswana & 5 \\
\hline Zulu & 3 \\
\hline Pedi & 3 \\
\hline \multicolumn{2}{|l|}{ Marital status } \\
\hline Single & 8 \\
\hline Married & 1 \\
\hline Cohabitation & 2 \\
\hline \multicolumn{2}{|l|}{ Employment } \\
\hline Employed & 5 \\
\hline Unemployed & 2 \\
\hline Self-employed & 4 \\
\hline \multicolumn{2}{|c|}{ Number of terminated pregnancies } \\
\hline 1 & 10 \\
\hline 3 & 1 \\
\hline \multicolumn{2}{|c|}{ Age at first termination of pregnancy } \\
\hline 15 years & 2 \\
\hline 16 years & 2 \\
\hline 18 years & 3 \\
\hline 19 years & 4 \\
\hline
\end{tabular}
Source: Makutoane, M.E., 2016, 'Choice on termination of pregnancy: Its impaction
woman's health', Unpublished dissertation. University of South Africa, Pretoria. 


\section{Delayed post-traumatic growth}

Post-traumatic growth is the ability to attain deep and progressive personal development. This development has an impact on relationships, appreciation for life, growth, functioning and self-perception as a strong person following a traumatic event such as terminating a pregnancy or living in poverty, amongst others (Tsai et al. 2016). With age and consequent life experiences, people experience more posttraumatic growth (Nuccio \& Stripling 2021).

All the participants in the study experienced delayed post-traumatic growth because none of them had fully embraced their circumstances after terminating a pregnancy in adolescence. Participants shared:

'I still feel guilty when I see children who may have been of my daughter's age, and I cannot talk to anyone at home or even my partner. I feel it will be better if I had gone through some cleansing ritual to help me adapt.' (N9, 26-year-old who terminated a pregnancy at 15)

'I feel such great antipathy towards my boyfriend. He now wants a baby and when I get pregnant, I go behind his back and terminate it. I had already terminated three, I can't help it. I cannot allow myself to hold a baby in my hands. God will punish me for it.' (N6, 26-year-old who terminated a pregnancy at 19)

'My grandmother was a Sangoma (traditional doctor), and I now see her all the time when I have conjugal rights with my husband like she wants to know why I aborted my first child. As my husband does not know what I did in adolescence, I feel so much guilt.' (N11, 36-year-old who terminated a pregnancy at 16)

\section{Low body esteem}

Low body esteem was another finding of the study and was defined in the way the participants understood their worth in relation to cultural expectations. Body esteem correlates with self-esteem and lower body esteem reflects lower self-esteem (Olenik-Shemesh, Heiman \& Keshet 2018). The following narrative quotes support this finding:

'I feel ugly and inhuman, my ugliness is within me, how can I as a woman live my life as if nothing has happened? The termination of pregnancy has left me with an emptiness inside, all I do is eat and walk around, how I look physically no longer matters to me.' (N2, 30-year-old woman who terminated a pregnancy at 18)

'In my culture, there is a saying that "a woman is regarded as a woman if she can protect her babies from conception to adulthood" What did I do? I have failed this simple and well-known idiom in my culture. I terminated my pregnancy when I was 4 months pregnant ... It was not performed in the hospital, and it was carried out by my mother, it was a boy ... I looked and my mother was wrapping it in a cloth. I can never forget that picture, it makes me feel like a true murderer. Since then I no longer care about myself as a person, I feel I do not deserve anything good in life.' (N8, 24-year-old woman who terminated a pregnancy at 15)

\section{Alteration in the development of a maternal identity}

An alteration in the development of a maternal identity was another theme that emerged from the analysis. The development of a maternal identity is the process of adopting maternal behaviours (Özkan \& Polat 2011). In this study, participants felt they were unfit to be mothers, yet they all experienced the cultural expectation of bearing and raising children. The participants shared the following statements in this regard:

'How do I even call myself a woman when I could not raise my baby? I look at other women who struggle and still manage to have children and accepted them as God's gift, why couldn't I do that.' (N10, 35-year-old who terminated a pregnancy at 19)

'I feel less than a woman and my partner also affirms that from the remarks he says about my mothering ability. According to him, I should not have had babies (referring to the two I had after termination). He is probably telling the truth.' (N5, 32-year-old woman who terminated a pregnancy at 19)

\section{Discussion}

The purpose of this study was to explore the interaction of culture and grief amongst women who terminated a pregnancy in adolescence. This study was designed to gain an understanding of the role played by culture in resolving grief and how culture and grief interact amongst women who terminated a pregnancy in adolescence. Participants' delayed post-traumatic growth demonstrated how intertwined culture and grief are for women who terminated a pregnancy. The African cultural system believes that the deceased are alive in the spiritual world of the living dead. Consequently, many Africans believe death rituals are meant to ease the deceased's transition from the world of the living to the world of the living dead. These rituals ensure peaceful relations between the living and the living dead, whereby the living dead remain connected to their families and community members (Baloyi \& Makobe-Rabothata 2014; Lagat 2018). It is believed that failure to observe these rituals could result in various calamities befalling the family or individuals (Ezenweke 2008).

All participants did not engage in any rituals, either because they did not know about them or the rituals conflicted with their Christian faith. Obare (2019) determined that some death rituals can creatively and harmoniously be incorporated and performed within Christian churches. Some participants in this study expressed that cultural practices are important because the termination of a pregnancy is a death experience. Different rituals assist the bereaved in accomplishing healing, for instance, informing others of the death and thereby reaching out for support, accepting the parting of a loved one, sharing the pain of grief with family and the community, adjusting to life after the loss and resuming normal functioning as individuals, as family, and as a community (Obare 2019).

Women who terminated their pregnancies carry the burden of hiding their grief from their support system and lack adherence to symbolic behaviours, which according to one's culture, surpasses family virtues.

Despite the counselling some participants received before and after terminating their pregnancy, they still struggled with the loss. Their interpersonal relationships and their selfworth continued to suffer (Coleman et al. 2007). This is a clear demonstration of their delayed post-traumatic grief. 
The second theme that emerged from the findings related to participants' low body esteem. Body image is the mental representation of the individual's attitude dimension, which is related to behaviours such as overeating and thoughts and feelings about one's physical appearance (Cash \& Smolak 2011). This statement affirms what the participants reported during their interviews.

Participants understood their value as women in relation to the cultural expectation of protecting their babies from conception to adulthood, a responsibility they failed to uphold. This perception caused them to neglect their physical appearance and had adopted an 'I do not care how I look' attitude, which did not help their self-esteem. Body esteem and self-esteem are closely related as indicators of well-being; therefore, a woman with high self-esteem also has high body esteem. According to Maslow's hierarchy of needs, one must have positive self-esteem to attain a high level of functioning. Women who terminated a pregnancy in adolescence may find that their body esteem has been altered, resulting in a proneness to psychological distress (Olenik-Shemesh et al. 2018).

The final theme that emerged from the data analysis was an alteration in the development of a maternal identity. The development of a maternal identity reflects a transition from feelings associated with pregnancy, which may include hope, distress and fear, the attainment of and coping with a maternal role (Hendricks-Munoz \& Mayers 2014). A motherhood identity takes cognisance of the composite interaction between individuals within their socio-cultural context (Abrams \& Curran 2011). In Africa, specifically South Africa, a woman is expected to share her maternal experiences with peers and family, ask for assistance and read about maternal expectations to develop a maternal identity (GrossSpector \& Cinamon 2018). In this study, the women had to hide their pregnancy; those who did not hide it were rebuked for being pregnant and were therefore not supported. This lack of culturally expected support altered their maternal identity. Support is rated as the most important facilitator of maternal role development (Kendall-Tackett 2014).

\section{Conclusion}

The purpose of this study was to explore the interaction of culture and grief amongst women who terminated a pregnancy in adolescence. It was determined that culture plays a vital role in participants' experiences of grief because their failure to observe cultural practices often led to prolonged grieving. A lack of support from significant others before and after terminating a pregnancy altered participants' development of a maternal identity. Delayed grieving caused participants to neglect their bodies, which was detrimental to their self-esteem and well-being. The study also revealed the lack of knowledge amongst young women about death rituals and their meaning and importance in resolving grief.

This research contributes to the growing body of knowledge that highlights the importance of culture in the many spheres of life, including aspects of grief. It further affirms the notion that distress often occurs because of a clash between two competing concepts, in this context, culture and grief.

\section{Limitations of the study}

The small sample makes it difficult for this study to be generalised. The sample was small because the researcher experienced difficulty accessing participants who were willing to share information on this sensitive topic.

The study was qualitative by nature; however, the themes that emerged might be better measured quantitatively, using questionnaires from existing instruments, such as the maternal alteration sub-scale. The author notes that this study could form the basis of a larger quantitative study that explores these sub-scales.

\section{Acknowledgements}

The author expresses her appreciation to Prof. G.B. Thupayagale-Tshweneagae of the Health Studies Department of the University of South Africa for her support of this work.

\section{Competing interests}

The author declares that she has no financial or personal relationships that may have inappropriately influenced her in writing this article.

\section{Author's contributions}

B.R.S. conceptualised the study, collected data, analysed and wrote the manuscript.

\section{Ethical considerations}

The ethics committee of the Department of Health Studies affiliated to the University of South Africa (Ref: HSHDC /564/ 2016), approved the study and the Research Ethics Committee approved the study's protocol. The research proposal was approved by the Institutional Review Board of the Department of Health, Tshwane Regional Research Ethics Committee, representing the Community Health Centre (Ref: GP_2017RP 19112). The study was fully explained to the participants, and their right to confidentiality, anonymity and freedom to withdraw from the study at any given time was emphasised throughout the study. Data were collected once the participants had given their verbal consent and signed the consent form.

\section{Funding information}

This research received no specific grant from any funding agency in the public, commercial or not-for-profit sectors.

\section{Data availability}

Data will be available from the corresponding author, B.R.S., on reasonable request. 


\section{Disclaimer}

The views and opinions expressed in this article are those of the author and do not reflect the official policy or position of the University of South Africa, and the publisher.

\section{References}

Abrams, L.S. \& Curran, L., 2011, 'Maternal identity negotiations among low-income women with symptoms of postpartum depression', Qualitative Health Research 21(3), 373-385. https://doi.org/10.1177/1049732310385123

Baloyi, L. \& Makobe-Rabothata, M., 2014, 'The African conception of death: A cultural implication', in L.T.B. Jackson, D. Meiring, F.J.R. Van de Vijver, E.S. Idemoudia \& W.K. Gabrenya Jr. (eds.), Toward sustainable development through nurturing diversity: Proceedings from the 21st International Congress of the International Association for Cross-Cultural Psychology, Stellenbosch, South Africa, July 17-21, 2012, pp. 261-271, viewed 07 February 2021, from https://scholarworks.gvsu. edu/iaccp_proceedings/1/.

Berg, B.L., 2001, Qualitative research methods for the social sciences, 4th edn., Allyn and Bacon, Boston.

Bruce, E.S., Lunt, L. \& McDonagh, J.E., 2017, 'Sleep in adolescents and young adults', Clinical Medicine 17(5), 424-428. https://doi.org/10.7861/clinmedicine.17-5-424

Cash, T.F. \& Smolak, L., 2011, Body image, A handbook of science, practice, and prevention, 2nd edn., The Guilford Press, New York, NY.

Cohen, N. \& Arieli, T., 2011, 'Field research in conflict environments: Methodological challenges and snowball sampling', Journal of Peace Research 48(4), 423-435. https://doi.org/10.1177/0022343311405698

Coleman, P.K., Readon, D.C., Strahan, T. \& Cougle, J.R., 2007, 'The psychology of abortion: A review and suggestions for future research', Psychology and Health 20(2), 237-271. https://doi.org/10.1080/0887044042000272921

Delahanty, Jr., E.J. \& Washburn, A., 2014, 'Grieving in psychopathology', in P. Moglia (ed.), Salem health: Psychology and mental health, pp. 861-864, Salem Press, New York, NY.

De Oliveira Cardoso, E.A., De Almeida da Silva, B.C., Dos Santos, J.H., Dos Santos Lotério, L., Accoroni, A.G. \& Dos Santos, M.A., 2020, 'The effect of suppressing funeral rituals during the COVID-19 pandemic on bereaved families', Revista Latino-Americana de Enfermagem 28, e3361. https://doi.org/10.1590/1518-8345.4519.3361

Doka, K.J., 2009, 'Disenfranchised grief', Bereavement Care 18(3), 37-39. https://doi. org/10.1080/02682629908657467

Ezenweke, E.O., 2008, 'The cult of ancestors: A focal point for prayers in African traditional communities', Journal of Religion and Humanities 1, 46-60.

Genevro, J.L., Marshall, T. \& Miller, T., 2004, 'Report on bereavement and grief research', Death Studies 28(6), 491. https://doi.org/10.1080/07481180490461188

Gross-Spector, M. \& Cinamon, R.G., 2018, 'Assessing adults' career exploration: Development and validation of the vocational and maternal identity exploration scales', Journal of Career Development 45(1), 19-33. https://doi.org/10.1177/ 0894845316667846

Hendricks-Munoz, K.D. \& Mayers, R.M., 2014, 'A neonatal nurse training program in kangaroo mother care (KMC) decreases barriers to $\mathrm{KMC}$ utilization in the NICU', American Journal Perinatol 1(11), 987-992. https://doi.org/10.1055/s-0034 1371359

Hoy, W.G., 2013, Do funerals matter? The purposes and practices of death rituals in global perspective, 1st edn., Routledge, New York, NY. https://doi.org/10.4324/ 9780203072745

Kaewkungwal, J. \& Adams, P., 2019, “Ethical consideration of the research proposal and the informed-consent process: An online survey of researchers and ethics committee members in Thailand', Accountability in Research 26(3), 176-197. https://doi.org/10.1080/08989621.2019.1608190
Kendall-Tackett, K., 2014, 'Birth trauma: The causes and consequences of childbirthrelated trauma and PTSD', in D.L. Barnes (ed.), Women's reproductive mental health across the lifespan, pp. 177-191, Springer, Cham. https://doi.org/10.1007/978-3-319across the $05116-110$

King, L., 2013, 'In discourse-towards a Pan-African psychology: Drum rolls for a psychology of emancipation', Journal of Black Psychology 39(3), 223-231. https:// doi.org/10.1177/0095798413478076

Kinghorn, A., Shanaube, K., Toska, E., Cluver, E. \& Bekker, L., 2018, 'Defining adolescence: Priorities from a global health perspective', The Lancet Child and Adolescent Health 2(5), e10. https://doi.org/10.1016/S2352-4642(18)30096-8

Lagat, D.K., 2018, 'Luhya burial rituals versus biblical view of life after death: Finding balance', African Multidisciplinary Journal of Research 2(2).

Loi, U.R., Lindgren, M., Faxelid, E., Oguttu, M. \& Klingberg-Allvin, M., 2018, 'Decisionmaking preceding induced abortion: A qualitative study of women's experiences in Kisumu, Kenya', Reproductive Health 15(1), 1-12. https://doi.org/10.1186/ s12978-018-0612-6

Makutoane, M.E., 2016, 'Choice on termination of pregnancy: Its impact on the woman's health', Unpublished dissertation. University of South Africa, Pretoria.

National adolescent sexual and reproductive health rights framework strategy 2014-2019', Health e-News, 19 November, 2015.

Nuccio, A.G. \& Stripling, A.M., 2021, 'Resilience and post-traumatic growth following late life polyvictimization: A scoping review', Aggression and Violent Behaviour 57, 101481. https://doi.org/10.1016/j.avb.2020.101481

Obare, P.K., 2019, 'The practise of death rituals as a native healing method for grief: A study of the Bukusu Community in Kenya' Unpublished thesis, University of Innsbruck.

Obasi, E., 2002, Reconceptualizing the notion of self from the African deep structure. Counseling persons of African descent: Raising the bar of practitioner competence, pp. 52-74, SAGE, Thousand Oaks, CA.

Olenik-Shemesh, D., Heiman, T. \& Keshet, N.S., 2018, 'The role of career aspiration, self esteem, body esteem, and gender in predicting sense of wellbeing among emerging adults', The Journal of Genetic Psychology 179(6), 343-356. https://doi. org/10.1080/00221325.2018.1526163

Özkan, H. \& Polat, S., 2011, 'Maternal identity development education on maternity role attainment and my baby perception of Primiparas', Asian Nursing Research 5(2), 108-111. https://doi.org/10.1016/S1976-1317(11)60019-4

Riessman, C.K., 2008, Narrative methods for the human sciences, 2nd edn., Sage, Boston. ISBN: 978-0-7619-2998-7.

Sawyer, S.M., Azzopardi, P.S., Wickremarathne, P.S.D. \& Patton, G.C., 2018, 'The age of adolescence', The Lancet Child \& Adolescent Health 2(3), 223-228. https://doi. org/10.1016/S2352-4642(18)30022-1

Souza, C.P. \& Souza, A.M., 2019, 'Funeral rituals in the grief process: Meanings and functions', Psicologia Psic.: Teor. e Pesq. 35, 1-7. https://doi.org/10.1590/ 0102.3772e35412

Swan, L.E.T., Rouland, R.S., Sperlich, M., Ely, G.E. \& Walters, C., 2021, 'Looking back looking forward: Examining the processing of abortion experiences using public abortion narratives', Journal of Women and Social Work 36(2), 204-219. https:// doi.org/10.1177/0886109920944533

Trahar, S., 2009, 'Beyond the story itself: Narrative inquiry and autoethnography in intercultural research in higher education', Forum: Qualitative Social Research 10(1), 1-20.

Tsai, J., Sippel, L.M., Mota, N., Southwick, S.M. \& Pietrzak, R.H., 2016, 'Longitudinal course of posttraumatic growth among U.S. military veterans: Results from the National Health and Resilience in Veterans Study', Depression and Anxiety 33(1), 9-18. https://doi.org/10.1002/da.22371

Wang, X., Elston, R.C. \& Zhu, X., 2011, 'The meaning of interaction', Human Heredity 70(4), 269-277. https://doi.org/10.1159/000321967

Weiten, W., 2013, Psychology: Themes and variations, 9th edn., Wadsworth, Cengage Learning, Boston, MA.

World Health Organization (WHO), 2020, Adolescent pregnancy, World Health Organization, Geneva. 